\title{
Fuel Filter Data Monitoring and Auto Switching at Komatsu Engine with Arduino to Improve Life Cycle Time Main Fuel Filter Usage
}

\author{
Galih Subekti \\ Department of Mechanical Engineering \\ Swiss German University \\ Tangerang 15143, Indonesia \\ Email: galihas@unitedtractors.com
}

\author{
Dena Hendriana \\ Department of Mechanical Engineering \\ Swiss German University \\ Tangerang 15143, Indonesia
}

\author{
Edi Sofyan \\ Department of Mechanical Engineering \\ Swiss German University \\ Tangerang 15143, Indonesia
}

\begin{abstract}
Diesel engines are the main components used in many sectors from automotive, industry to manufacturing. Diesel engines have many advantages including being able to produce large power on low engine turns. Diesel engines use diesel fuel. Where this diesel fuel must be ensured that it is always clean. So the role of the fuel filter is very important to ensure the performance of the diesel engine. The ability of the fuel filter will decrease in its function to filter out impurities in the fuel path. So that this fuel filter must be replaced periodically according to its operating hours. This tool is made to optimize the use of fuel filters in accordance with the conditions of the clogged. This tool will work to monitor the fuel filter clogged condition by calculating the pressure read by the controller before and after passing the fuel filter. If the clogged has reached $70 \%$, the controller will automatically activate the solenoid valve to change the use of the fuel filter from the main fuel filter to the backup fuel filter. So that in this way the use of the fuel filter will be more optimal in accordance with the actual conditions of the clogged.
\end{abstract}

Keywords: Auto Switching, Engine Vibration, Fuel Pressure, Arduino, Solenoid Valve, Science Jurnal, Fuel Filter.

\section{INTRODUCTION}

Diesel engines are one component that plays a very important role as a generator of power in various equipment. Both in the manufacturing, automotive industry and for construction equipment and many more. In construction equipment, the engine is a vital component that will provide a good source of energy to be transmitted to the mechanical (transmission) or change to hydraulic power. A diesel engine is an internal combustion engine that uses compression heat to create ignition and burn fuel that has been injected into the combustion chamber. This machine does not use spark plugs such as gasoline engines or gas engines. This machine was discovered in 1892 by Rudolf Diesel, who received a patent on February 23, 1893. To ensure a perfect combustion process, it is necessary to ensure that the diesel fuel entering the system (Fig.1) must be in a clean condition and free from dirt. Because what is in the fuel, besides it will cause combustion to become imperfect, it can also cause damage to the fuel lines in the Diesel engine. So that the Diesel engine is installed a fuel filter
(Fuel Filter) which serves to filter out impurities contained in the fuel so as not to enter into the combustion system. This fuel filter is installed on the track after the fuel pump and before the fuel manifold. This fuel filter is very vulnerable to dirt, because it has small filtering pores. So that the Diesel Engine installed 2 fuel filters installed in series. In this fuel filter is not equipped with bypass valve (bypass valve) because it is not permitted for the slightest dirt can pass and enter the combustion system because it will cause fatal damage to the component.

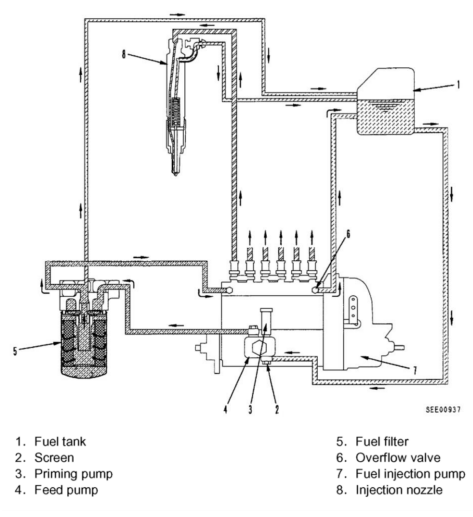

Fig. 1. Fuel System Flow at Komatsu Engine SAA4D102.

\section{LITERATURE REVIEW}

\section{A. Pressure for Indicator of Fuel Filter Clogging}

Clogging experiment has run and monitored till the pressure drop (e.g. Differential Pressure, $\Delta \mathrm{P}$ ) has reached to peak value and remains stable. Basically $\Delta \mathrm{P}$ values calculated as subtracting the pressure values obtained from pressure 

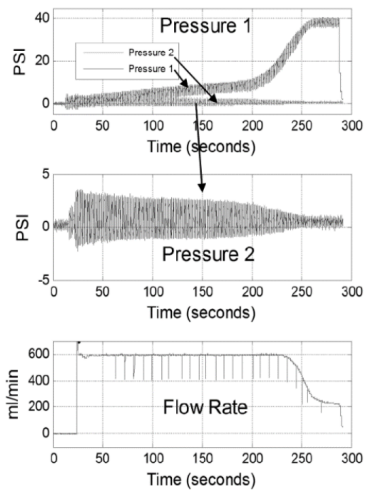

Fig. 2. Pressure Value for Fuel Filter Clogging.

sensor 1 (i.e. upstream pressure) from the pressure sensor 2 (i.e. downstream pressure) values. Upstream pressure and $\Delta \mathrm{P}$ values show similar degradation profile since pressure values collected from pressure sensor 2 are quite low range compared to upstream pressure. Upstream and downstream pressure values show linear degradation for the majority of lifetime and exponential degradation behaviors are seen after that as shown in plot 1 and plot 2 in Figure 2.

\section{B. Filtering Mechanism}

Filtration is basically described as a unit operation that is separation of suspended particles and fluid utilizing a medium where only the liquid can pass (Cheremisinoff, 1998). Sharing an important role with pumps, fuel filters filtrate dirt, contaminants in the fuel system such as rust \& dust particulate which has been released by holding tank, pipe work, paint chips, tank moisture, or other numerous type of dirt has been delivered via the supply tanker (Wilfong et al., 2010). Consequences like engine \& pump performance reduction due to increased abrasion and inefficient burning in the engine are the main motivation for necessity of fuel filtration. System flow rate and engine performance decreases once a fuel filter is clogged where it doesn't function well in its desired operation ranges. The difference in between clogged and clean mesh is visible. Fuel filters replaced \& cleaned on a regular basis. Monitoring and implementation of prognostics have the potential to avoid costs and increase safety.

$$
k=\frac{Q \mu t}{A \Delta P}
$$

where: $\mu=$ Fluid viscosity [Pa.s], $t=$ Filter thickness [m], $\mathrm{A}=$ Filter area $\left[\mathrm{m}^{2}\right], \Delta P=$ Pressure drop $[\mathrm{Pa}], \mathrm{Q}=$ Flow rate $\left[\mathrm{m}^{3} / \mathrm{s}\right]$

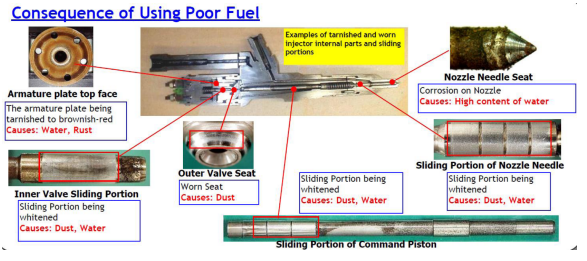

Fig. 3. Sample of Component Damage.

\section{Effect of Main Fuel Filter Clogging}

The effect of the damage (Fig.3) to the fuel filter that causes dirt to enter the system will have a vital effect and damage the components in the engine system. The most risky damage if the fuel filter fails at work is damage to the injector. Below are some examples of damage from fuel injectors due to impurities that are not filtered by fuel filters.

In a study conducted by Researchgate (2013) in an article entitled "Filter Clogging Data Collection for Prognostics", explaining that contaminants contained in fuel will cause a decrease in engine performance and cause wear on the fuel pump. So that the blockages that occur in the filter will be monitored through flow rates and pressure from the fuel. The flow rate and the amount of fuel pressure will change when there is a blockage in the fuel filter. The value of pressure and flow rate are considered as health indicators of filter degradation. The pressure difference across filters is expected to increase and the flow rate is expected to decrease during the blockage process. The clogging process is done by taking data using a pressure sensor in the filter path and a flow sensor that is installed after the fuel.

\section{RESEARCH METHODS}

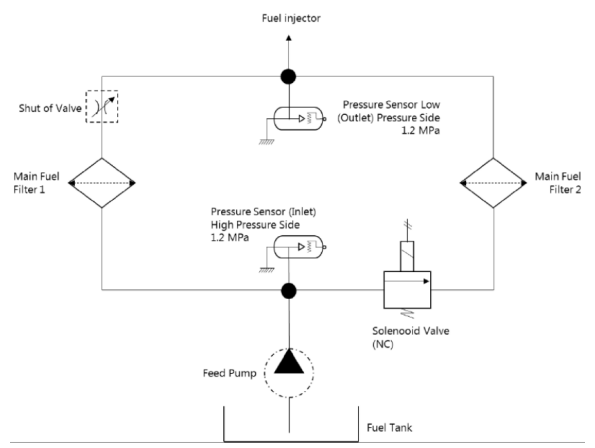

Fig. 4. Tools Fuel Filter Data Monitoring \& Auto Switching Schematic Diagram. 
The battery is the voltage source used in this tool by 5 volts, then it will be distributed throughout the circuit such as sensors, microcontrollers, Liquid Crystal Display (LCD). After the tool is active the pressure sensor will read the pressure of fuel that will enter into the fuel filter. There are 2 pressure sensors installed before and after the fuel filter to read the Clogged from the fuel filter by means of the microcontroller reading the difference in pressure from the pressure sensor before and after the fuel filter. After being read by the microcontroller, the sensor output will be processed and displayed on the LCD. When the pressure difference read by the pressure sensor inlet and the outlet has indicated the fuel filter 1 Clogged, the microcontroller will give an order to the solenoid valve to activate and flow the fuel flow from filter 1 to filter 2 . This solenoid valve works with $12 \mathrm{~V}$ voltage.

\section{A. Testing Pressure Sensor}

From the data (Fig.5-6), it can be seen that the data read by the pressure sensor does not fluctuate or can be said to be stable and there is no noise from the sensor that interferes with the reading of the data. This is also proven by comparing data from vibration engines to the results of reading pressure sensors inlets and outlets. Collecting vibration engine data by using the Science Journal application installed on Mobile. Data recorded by science journals is the result of reading from he accelerometer that is on a Hand Phone. Where the results of the analysis of the comparison of data vibration and fuel pressure are not related. The analysis is done using the scatter graph method.

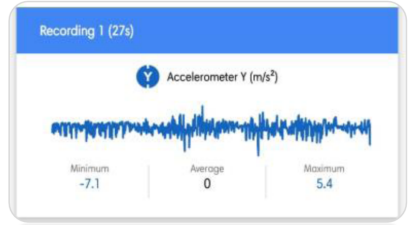

Fig. 5. Data Engine Vibration.

From the recorded data, then the relationship between vibration engine and pressure fuel is sought. Analyze this data using the SCATTER method and analyze the $\mathrm{R}$ value to see the relationship or influence between engine vibration and the reading of the pressure sensor value. If the value of $\mathrm{R} ; 0$ means that it does not have a causal relationship, and if the value of $\mathrm{R}$ approaches 1 then it has a strong relationship between cause and effect. So the scatter diagram data above, it is said that between engine vibration and fuel pressure do not have a causal relationship. This is stated by the value of $\mathrm{R}$ which is quite small, namely 0.0006 for the relationship between vibration engine and outlet pressure and 0.0004 for the relationship between vibration engine and inlet pressure.

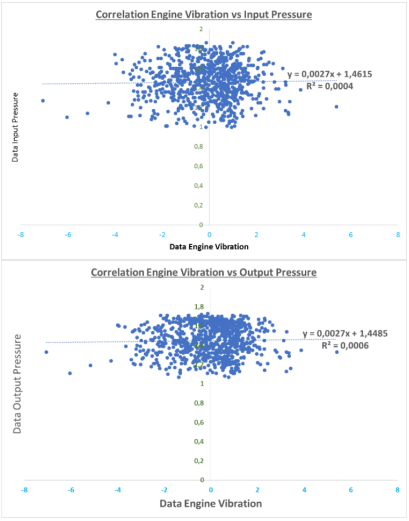

Fig. 6. Correlation Engine Vibration vs Fuel Pressure.

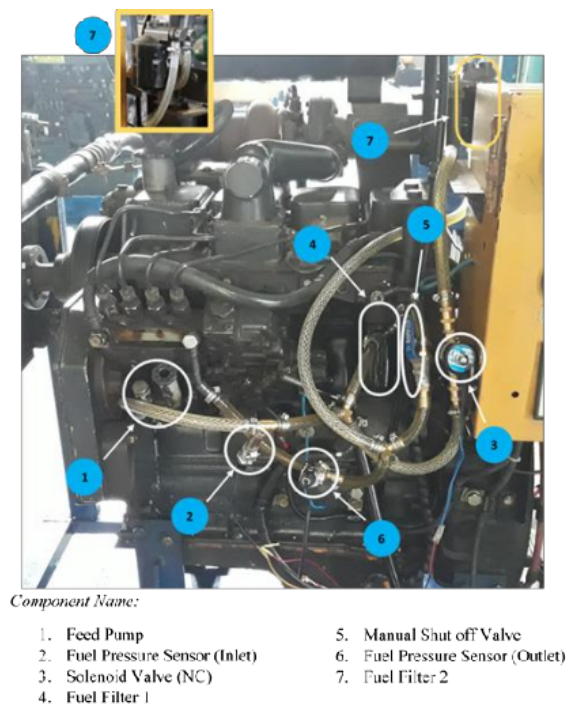

Fig. 7. Tools Installation on Komatsu Engine.

\section{Results \& Discussions}

The following is the actual data displayed by Nextion LCD. This experiment to simulate the transfer of fuel filter 1 from fuel filter 1 to fuel filter 2 is to use a manual valve. This is done to simulate the Clogged condition of the fuel filter 1 by inhibiting the flow of filter output 1 . This condition will be 
read by Nextion LCD when the Clogged reaches $70 \%$, then the Arduino will send a current to the solenoid valve for active, so that the fuel flow moves from filter 1 to 2 . The reason for taking the value of $70 \%$ is based on the experiment, when the fuel filter 1 is blocked, when the value reaches $75 \%$ above the engine has begun to experience abnormal / unnatural rounds of symptoms. So as a safe step, before achieving this condition, it is set at $70 \%$ for the fuel filter replacement process.

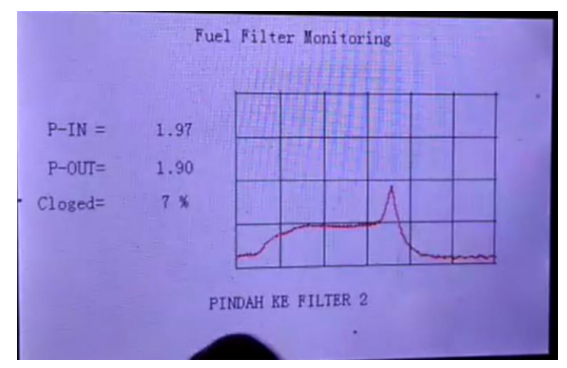

Fig. 8. Switching Process from Filter 1 to Filter 2

The above is carried out to optimize the use of fuel filters. The condition that occurs at this time is that the fuel filter must be replaced according to the service life in operating hours. This fuel filter is replaced every 500 hours of operation, which means that under any conditions, when the service is reached, the fuel filter must be replaced. In this experiment, it was carried out with the aim of extending the life of fuel filter usage. Where the fuel filter will be replaced by reference is the clogged level detected by the sensor. In this case, when $70 \%$ of clogged is detected, the microcontroller will automatically give a command to the solenoid valve to change the fuel path from the fuel filter 1 (main) to the fuel filter 2 (reserve). With this mechanism, the fuel filter can be increased according to the level of clogged detected by the system. As for the procedure, if the system has auto switching from filter 1 to filter 2, then the operator must replace filter 1 and reset the system to restore it to its original state.

\section{CONCLUSION}

First, the experimental results above proved very useful for extending the life of the fuel filter. Where the system is made is to auto switching the main fuel filter to the backup fuel filter based on the clogged level. So that the filter life can be used longer, because the replacement is no longer based on the hours of use, but based on the conditions of the fuel filter itself. this tool works by reading the pressure in the fuel line and comparing the pressure before and after the fuel filter, then the microcontroller will calculate the clogged level and will activate the solenoid valve to change the fuel path from the main fuel filter to the backup fuel filter.

Secondly, the quality of the fuel filter in its duty to filter impurities in fuel, will continue to decrease with the usage hours. This can be seen from the fuel filter Clogged level indicator which will increase with increasing usage hours.

Finally, the use of the fuel filter can be optimized again beyond the recommendations issued by the manufacturer, because by monitoring the pressure in the fuel filter it can be known the Clogged condition of the fuel filter.

\section{RECOMMENDATION}

From the experiments carried out there are still several conditions that can still be optimized to obtain accurate data. Here are some recommendations for improvement on this system:

1) Monitor pressure in the fuel filter, using a filter that has been used for 500 hours with conditions running continuously on the engine until it is completely Cloggeded.

2) Experiments are carried out in the engine that is not installed on the unit of the machine, so that to get nearactual data, a system installation can be performed on the engine installed in the device.

3) This tool only monitors the condition of the fuel filter Clogged by taking pressure data only. If you want to get more complete data, the condition of the filter can be done by monitoring the quality of the fuel used.

4) In Figure 8 the graph increase is very sudden, this is due to disproportionate valve shut-off opening. So to get better data, the opening of the shut-off valve must be done

\section{REFERENCES}

[1] Komatsu, Shop Manual Bulldozer D85ESS-2A

[2] Techno Training Center Komatsu, Special High Efficiency Fuel Filter

[3] Techno Training Center Komatsu, Filter Management

[4] O. F. Eker, F. Camci, and I. K. Jennions, Filter Clogging Data Collection for Prognostics, Research Gate IVHM Centre, Cranfield University, UK , 2013.

[5] Chevron,Diesel Fuel Technical Review, 2007

[6] MA Grigor'ev, VV Sokolov, VN Efremov, PD Kasich, and SA, Influence Of Fuel Filterability On Diesel Engine Filters, 1975

[7] Jochen Reyinger, Michael Durst and Gunnar M. Klein, Fuel Filters for Future Diesel and Petrol Engines with Direct Injection, 2004

[8] Robert E. Bicking, Pressure Sensors, Honeywell Micro Switch.

[9] G.B. Bessee, S.R. Westbrook, L.L. Stavinoha, Automotive Diesel Fuel / Filter Quaification Methodology And Preliminary Screening Results, Interm Report BFLRF No. 265, 1992

[10] Allison, Changes in Diesel Fuel, The Service Technician Guide to Compression Fuel Ignition Quality, 2007

[11] Ayranci Hakan, Design And Performance Evaluation Of A Fuel Filter, Thesis Middle East Technical University, 2010.

[12] Pengenalan Tentang Arduino IDE, Indonesian Technology.

[13] Nextion Enhanced HMI Display,Nextion. Itead.cc, 2018. 